\title{
Effect of milling time on the structure, micro-hardness, and thermal behavior of amorphous/nanocrystalline TiNiCu shape memory alloys developed by mechanical alloying
}

\author{
Fatemeh Alijani ${ }^{\mathrm{a}}$, Rasool Amini ${ }^{\mathrm{a}, *}$, Mohammad Ghaffari $^{\mathrm{b}}$, Morteza Alizadeh ${ }^{\mathrm{a}}$, Ali Kemal Okyay ${ }^{\mathrm{b}}$ \\ ${ }^{a}$ Department of Materials Science and Engineering, Shiraz University of Technology, 71555-313 Shiraz, Iran \\ ${ }^{\mathrm{b}}$ Department of Electrical and Electronics Engineering, UNAM-Institute of Materials Science and Nanotechnology, Bilkent University, Ankara 06800, Turkey
}

\section{A R T I C L E I N F O}

\section{Article history:}

Received 5 June 2013

Accepted 3 September 2013

Available online 27 September 2013

\section{Keywords:}

TiNiCu shape memory alloys

Mechanical alloying

Crystal structure

Microstructure

Micro-hardness

Crystallization

\begin{abstract}
A B S T R A C T
In the present paper, the effect of milling process on the chemical composition, structure, microhardness, and thermal behavior of $\mathrm{Ti}-41 \mathrm{Ni}-9 \mathrm{Cu}$ compounds developed by mechanical alloying was evaluated. The structural characteristic of the alloyed powders was evaluated by X-ray diffraction (XRD). The chemical composition homogeneity and the powder morphology and size were studied by scanning electron microscopy coupled with electron dispersive X-ray spectroscopy. Moreover, the Vickers microindentation hardness of the powders milled for different milling times was determined. Finally, the thermal behavior of the as-milled powders was studied by differential scanning calorimetery. According to the results, at the initial stages of milling (typically $0-12 \mathrm{~h}$ ), the structure consisted of a Ni solid solution and amorphous phase, and by the milling evolution, nanocrystalline martensite (B19') and austenite (B2) phases were initially formed from the initial materials and then from the amorphous phase. It was found that by the milling development, the composition uniformity is increased, the inter-layer thickness is reduced, and the powders microhardness is initially increased, then reduced, and afterward re-increased. It was also realized that the thermal behavior of the alloyed powders and the structure of heat treated samples is considerably affected by the milling time.
\end{abstract}

๑ 2013 Elsevier Ltd. All rights reserved.

\section{Introduction}

Equi-atomic NiTi compounds are widely used in medical $[1,2]$ and engineering applications [3-6], due to their shape memory effect (SME), superelasticity (SE) and biocompatibility [7,8]. However, these properties are significantly altered by a composition deviation and can be considerably improved by the addition of a third element (such as $\mathrm{Cu}$ ) to the binary compound. By the partial replacement of $\mathrm{Ni}$ with $\mathrm{Cu}$, not only the composition sensitivity of the alloy is reduced [8-10], but also the corrosion resistance of the alloy can be improved and the transformation behavior and shape memory characteristics can be affected. For instance, a two-stage transformation (cubic-B2 to orthorhombic-B19 and B19 to monoclinic-B19') occurs by the addition of 10 at.\% $\mathrm{Cu}$, whereas a one-stage transformation (B2-B19) occurs provided that the amount of $\mathrm{Cu}$ exceeds 10 at.\% [7,11]. Since the transformation hysteresis of $\mathrm{TiNiCu}$ intermetallic compounds is smaller than that of binary NiTi, these compounds are widely used in actuators [5,12].

\footnotetext{
* Corresponding author. Tel.: +98 917811 1858; fax: +98 7117354520 .

E-mail addresses: amini@sutech.ac.ir, ramini2002@gmail.com (R. Amini).
}

Although TiNiCu compounds are commonly produced by arc melting [13-15], several solid-state techniques like mechanical alloying (MA) [16-18] have been extensively used to synthesize these advanced materials. This is due to the fact that the production of the compounds by the melting process has some difficulties like segregation, unexpected grain growth, contamination from crucibles, and evaporation of the constituents [19]. By using MA as a processing method, not only the aforementioned limitations are avoided, but also the production of supersaturated solid solutions, nanocrystalline materials and amorphous phases [20] is possible. Ease of processing, alloying possibility at ambient temperature, and low processing cost are the additional advantages of MA [20]. However, the possibility of amorphization during MA can be detrimental to the shape recovery, since SME is attributed to the transformation of crystalline phases. Therefore, to show SME, the crystallization of the amorphous phase by a heating cycle is required after MA [21].

Although reports on the formation and characterization of TiNi intermetallics were available, there are limited reports [16-18] on the formation of TiNiCu by ball milling. Moreover, the exact mechanisms of alloying and phase transformations during milling and subsequent heat treatments have been not clearly addressed. 
Table 1

Chemical composition of the as-milled powders.

\begin{tabular}{|c|c|c|c|c|c|c|c|c|c|c|}
\hline \multirow[t]{3}{*}{ Milling time $(\mathrm{h})$} & \multicolumn{10}{|c|}{ Weight percent (wt.\%) } \\
\hline & \multicolumn{2}{|l|}{$\mathrm{Ni}$} & \multicolumn{2}{|l|}{$\mathrm{Ti}$} & \multicolumn{2}{|l|}{$\mathrm{Cu}$} & \multicolumn{2}{|l|}{$\mathrm{Fe}$} & \multicolumn{2}{|l|}{$\mathrm{Cr}$} \\
\hline & Con & $\mathrm{AE}$ & Con & $\mathrm{AE}$ & Con & $\mathrm{AE}$ & Con & $\mathrm{AE}$ & Con & $\mathrm{AE}$ \\
\hline 6 & 44.720 & 0.030 & 44.580 & 0.030 & 10.640 & 0.020 & 0.050 & 0.002 & 0.010 & 0.001 \\
\hline 24 & 44.680 & 0.030 & 44.570 & 0.030 & 10.660 & 0.020 & 0.077 & 0.002 & 0.013 & 0.001 \\
\hline 48 & 44.630 & 0.030 & 44.590 & 0.030 & 10.630 & 0.020 & 0.133 & 0.003 & 0.017 & 0.002 \\
\hline 96 & 44.570 & 0.030 & 44.570 & 0.030 & 10.650 & 0.020 & 0.189 & 0.003 & 0.021 & 0.002 \\
\hline
\end{tabular}

Con - concentration, AE - absolute error.

In this regard, the present paper focuses on possible phase transformations during the mechano-synthesis and subsequent heat treatment of TiNiCu compounds. Also, the effect of the phase transformations during milling on the hardness and thermal behavior of the samples is studied.

\section{Experimental procedures}

High-purity titanium (>99\%), nickel (>99.5\%) and copper ( $>99.9 \%)$ powders were mixed in an atomic ratio of 50:41:9 (44.56:44.79:10.65 wt.\%) and then mechanically alloyed in a planetary ball mill (Sepahan $84 \mathrm{D})$ with tempered steel vials $(90 \mathrm{ml})$ and balls $(5 \times 20 \mathrm{~mm}$ and $7 \times 10 \mathrm{~mm})$ under argon. The milling was conducted at room temperature with a milling speed of $450 \mathrm{rpm}$ and a ball-to-powder mass ratio of 20:1 up to $96 \mathrm{~h}$. In the present alloying system, due to ductile nature of the primary materials, an adherent thin coating of the powders is formed on the milling vial and balls. Accordingly, to prevent the excessive wear of the milling medium and to minimize the amount of contaminations, the powders obtained from the 3rd milling duration were used for the analysis.

In order to evaluate the variation of the compound stoichiometry, an X-ray fluorescence analyzer (XRF, Philips PW2400) was used and then the quantitative values were extracted by the PAN analytical software. Also, the amount of $\mathrm{Fe}$ and $\mathrm{Cr}$ contamination was estimated by using the inductively coupled plasma (ICP) testing. The structural properties of the powders were evaluated by powder X-ray diffraction (XRD, Pananalytical, X'pert Pro MPD) with the $\mathrm{Cu} \mathrm{Ka} \alpha_{1,2}(\lambda=0.154 \mathrm{~nm})$ radiation at $40 \mathrm{kV}$ and $40 \mathrm{~mA}$. The XRD data were collected at a step time of $3 \mathrm{~s}$ and a step size of $0.03^{\circ}$ in the $2 \theta$ range of $20-85^{\circ}$. The qualitative and quantitative analyses were performed by Match (version 2.0.5) and MAUD (version 2.26) software, respectively. In addition, the evolution of the powder morphology and size as well as their chemical homogeneity were studied by a scanning electron microscope (SEM, FEI, Nova Nanosem 430) coupled with energy dispersive X-ray spectroscopy (EDS). Moreover, in order to further understand the alloying mechanism during MA, the powders were compacted to small pellets ( $4 \mathrm{~mm}$ dia.) at $200 \mathrm{~Pa}$ pressure, then mounted and prepared for microhardness tests by polishing with some grit sandpapers (1200P and 2000P). Afterwards, Vickers ( $H v)$ microhardness measurements were made on a Suntech microhardness tester using an indentation load of $300 \mathrm{~g}$ for a dwell time of $10 \mathrm{~s}$ with. Vickers hardness was calculated as the applied load, $P$ (measured in $\mathrm{mN}$ ), over the surface area of the indentation, as measured by the long diagonal length of the indentation, $d$ (measured in $\mu \mathrm{m}$ ) [22]:

$H v=\frac{1854.4 P}{d^{2}}$

Since indentation results are often influenced by unavoidable statistical variations, each individual measurement in the present study is an average of five different measurements.
Finally, the milled powders were analyzed by a differential scanning calorimeter (DSC, 204FI) up to $630^{\circ} \mathrm{C}$ with an alumina container under a flowing purified helium gas atmosphere at a heating rate of $20^{\circ} \mathrm{C} / \mathrm{min}$. The heat released in the thermal analysis was taken after subtracting the second heating run from the first run. To verify the DSC results, selected samples were heated up to the predetermined temperatures similar to the heating procedure of DSC and then water quenched. Subsequently, the structure of the samples was evaluated by XRD and the selected area diffraction (SAD) pattern of a transmission electron microscope (TEM, FEI, Tecnai G2 F30).

\section{Results and discussion}

\subsection{Chemical composition analysis}

It is well-known that a main challenge in the MA process is the introduction of impurities (particularly iron) to the alloyed powders from the steel grinding medium and the steel container.

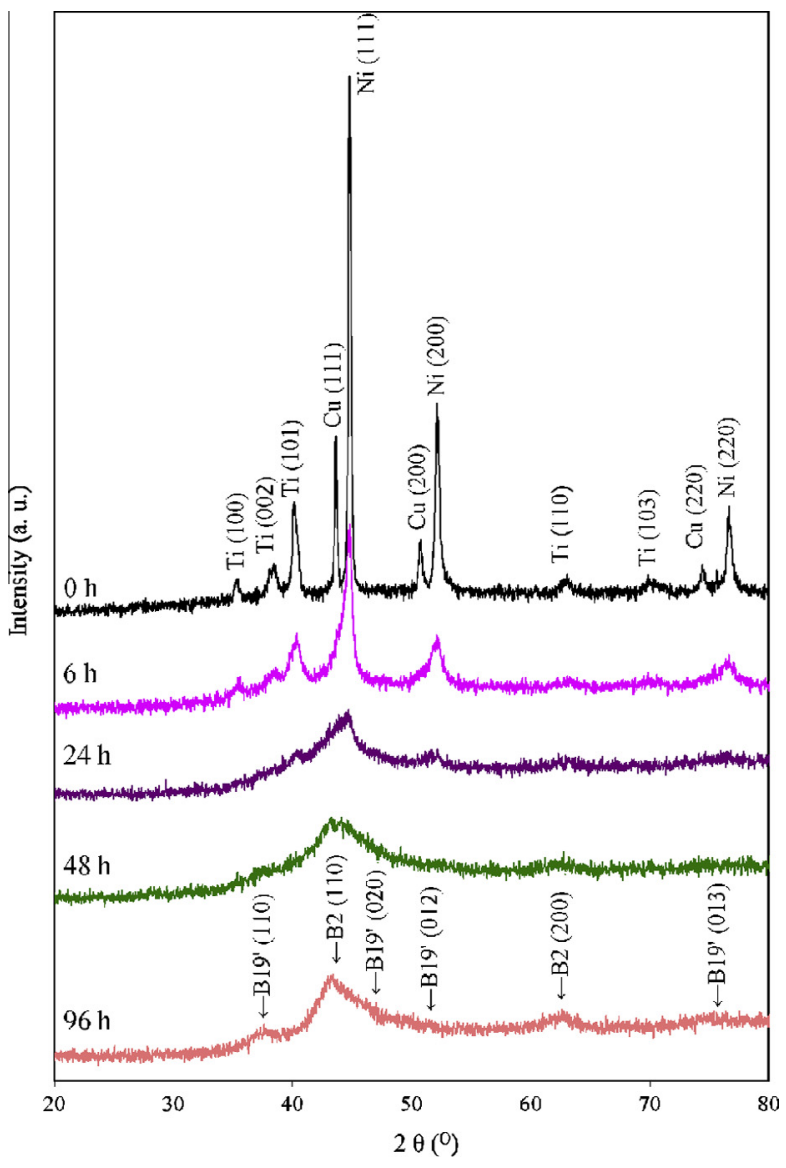

Fig. 1. XRD pattern of TiNiCu powders milled for various milling times. 
Table 2

Quantitative XRD results of the as-milled powders.

\begin{tabular}{|c|c|c|c|c|c|c|c|c|c|c|c|c|c|c|c|c|}
\hline \multirow[t]{2}{*}{ Milling time $(\mathrm{h})$} & \multicolumn{3}{|l|}{$\mathrm{Ni}$} & \multicolumn{3}{|l|}{$\mathrm{Ti}$} & \multicolumn{3}{|l|}{$\mathrm{Cu}$} & \multicolumn{3}{|l|}{ B19' } & \multicolumn{3}{|l|}{ B2 } & \multirow{2}{*}{$\begin{array}{l}\text { Amorphous } \\
\text { Wt.\% }\end{array}$} \\
\hline & $D$ & $\varepsilon$ & Wt.\% & $D$ & $\varepsilon$ & Wt.\% & $D$ & $\varepsilon$ & Wt.\% & $D$ & $\varepsilon$ & Wt.\% & $D$ & $\varepsilon$ & Wt.\% & \\
\hline 1 & 94 & 0.138 & 41 & 60 & 0.150 & 33 & 150 & 0.099 & 5 & & & & & & & 21 \\
\hline 6 & 68 & 0.600 & 37 & 52 & 0.400 & 14 & 99 & 0.360 & 4 & & & & & & & 45 \\
\hline 12 & 64 & 0.711 & 14 & 49 & 0.505 & 3 & 88 & 0.468 & 2 & 29 & 0.550 & 16 & 41 & 0.500 & 9 & 56 \\
\hline 24 & 60 & 0.800 & 4 & 45 & 0.550 & 1 & & & & 22.3 & 0.670 & 20 & 35.9 & 0.580 & 11 & 64 \\
\hline 48 & & & & & & & & & & 17.6 & 0.950 & 22 & 32.1 & 0.700 & 12 & 66 \\
\hline 72 & & & & & & & & & & 16.4 & 1.000 & 30 & 30 & 0.730 & 14 & 56 \\
\hline 96 & & & & & & & & & & 15 & 1.040 & 31 & 28.7 & 0.750 & 21 & 48 \\
\hline
\end{tabular}

D: Crystallite Size (nm), $\varepsilon$ : r.m.s microstrain (\%), Wt.\%: Weight Percent.

The magnitude of contamination depends on the time, intensity, and atmosphere of milling, as well as the difference in the strength/hardness of the powders and the milling medium. It has been reported that by the substitution of a considerable amount of Fe (e.g. 2.6 wt.\%) for Ni in Ti-Ni alloys, the martensitic transformation start temperature (Ms) is significantly reduced [16] and the pre-martensite phase (R-phase) is created prior to the martensite phase $\left(\mathrm{B} 19^{\prime}\right)$ formation [23]. Table 1 lists the variation of compound stoichiometry and the quantity of contaminations during the milling process. Concerning the result, it is evident that the expected nominal composition was achieved and the fraction of iron and chromium contaminations is significantly low (e.g. 0.189 wt.\% Fe and $0.021 \mathrm{wt} . \% \mathrm{Cr}$ for $96 \mathrm{~h}$ milled powders).

\subsection{Structural characterization}

Fig. 1 shows the XRD spectra of the as-milled powders as a function of milling time. As can be seen from the patterns, in the initial powders mixture, sharp diffraction peaks related to fcc-Ni, hcp-Ti and fcc-Cu are evident. By the milling initiation, due to the development of nano-sized structure and the introduction of the high level of micro-strain, the sharp peaks are considerably broadened. By further milling, the peaks of the initial materials gradually vanish, where the $\mathrm{Cu}$ and Ti peaks disappeared after 6 and $24 \mathrm{~h}$ of milling, respectively. The further analysis of the XRD profiles indicates that by increasing the milling time, because of the dissolution of $\mathrm{Cu}$ (atomic radius: $1.28 \AA$ ) and especially $\mathrm{Ti}$ (atomic radius: $1.47 \AA$ ) into the $\mathrm{Ni}$ (atomic radius: $1.24 \AA$ ) lattice and consequently the solid solution formation, the diffraction lines of $\mathrm{Ni}$ shift toward lower angles and the lattice parameter of fcc-Ni increases.

During milling, in order to reduce the internal strain and consequently the free energy of the system, ordered fcc-Ni can be transformed into disordered fcc and the amorphization process can occur [20]. Since the formation of the amorphous phase during MA depends on several factors such as the milling conditions and the alloying system, different amorphization reactions have been proposed [24]. Among them, the one consisting a shift in the peak position and a continuous broadening of the XRD peaks due to a continuous reduction of the effective crystallite size are responsible for amorphization of the present alloying system during MA.

According to the quantitative phase analysis results presented in detail in our previous paper [25] and also listed in Table 2, the existence of stress-induced martensite (SIM, B19') and B2 austenite is revealed even at short milling times $(12 \mathrm{~h})$, which can be due to severe plastic deformation and temperature rising during the milling cycle, respectively. In the XRD patterns of Fig. 1, it seems that due to the excessive peak broadening caused by lattice strain increasing, crystallite size decreasing, and amorphous phase extension, it is difficult to discriminate the B2 and B19 peaks from the other crystalline peaks.

Comparing the XRD patterns of 48 and $96 \mathrm{~h}$ powders in Fig. 1, it can be seen that the mechano-crystallization of the amorphous phase to the more stable crystalline B2 and B19' phases occurs during this milling interval. It can be attributed to the strain energy and possibly temperature increasing during MA [20].

\subsection{Microstructural evaluation}

Fig. 2 shows the SEM images of the TiNiCu alloys during the milling process. It is known that the MA process consists of three main stages: cold welding, fracturing, and steady-state condition [26]. As shown in Fig. 2(a), due to the high surface energy of the fine particles and consequently the domination of cold welding and agglomeration over fracturing mechanisms, irregular-shaped powders with a wide particles size distribution $(14-60 \mu \mathrm{m})$ are developed at the early stages of milling (e.g. $6 \mathrm{~h}$ ). By increasing the milling time, the powder particles are work hardened and due to the accumulation of strain energy [20], the particle hardness increases; therefore, the tendency of cold-welded powders for fracturing increases and the particles size is significantly reduced. Afterwards, a balance between the cold welding and fracturing rates is achieved and the particles size reaches its steady-state condition $[20,27]$, which is associated with the narrow particle size
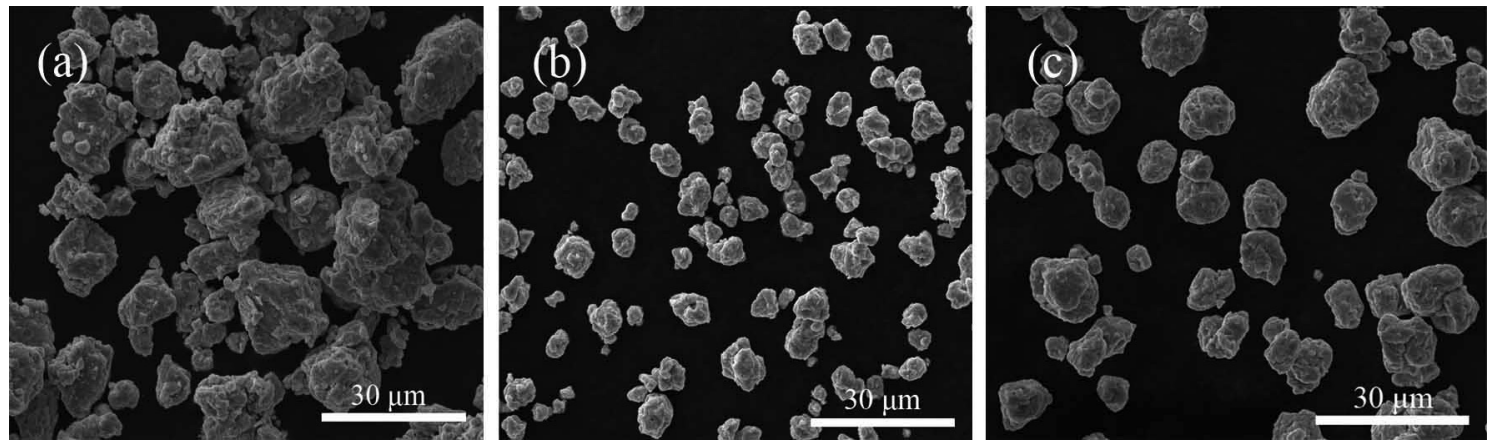

Fig. 2. SEM images of the $6 \mathrm{~h} \mathrm{(a),} 24 \mathrm{~h}$ (b), and $96 \mathrm{~h}$ (c) milled powders. 
distribution, equiaxed morphology [28], and saturation in hardness [26]. After sufficient milling times (Fig. 2(c)), by the occurrence of mechano-crystallization of the amorphous phase, the steady-state condition is altered and the particles tend to re-weld and their size is increased.

In order to study the elements distribution in the as-milled powders, EDS elemental mapping was done on selected powders.
Fig. 3(a) shows that at short milling times (e.g. $1 \mathrm{~h}$ ), the elements distribution is non-uniform, in which $\mathrm{Cu}$ is not present in the map spectrum. The EDS point spectrum correlated to the Ti-rich section of the map image clearly represents an inhomogeneous elements distribution, thereby indicating an insufficient milling time for alloying. In contrast, at sufficiently high milling times (e.g. $48 \mathrm{~h}$ ), the elements distribution is entirely uniform and no
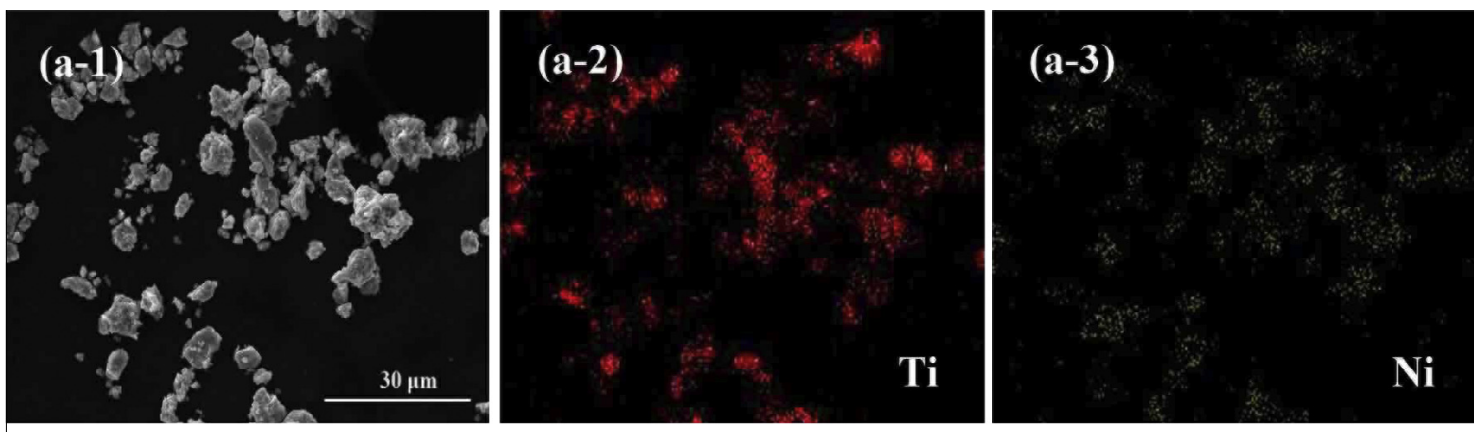

(a-4)
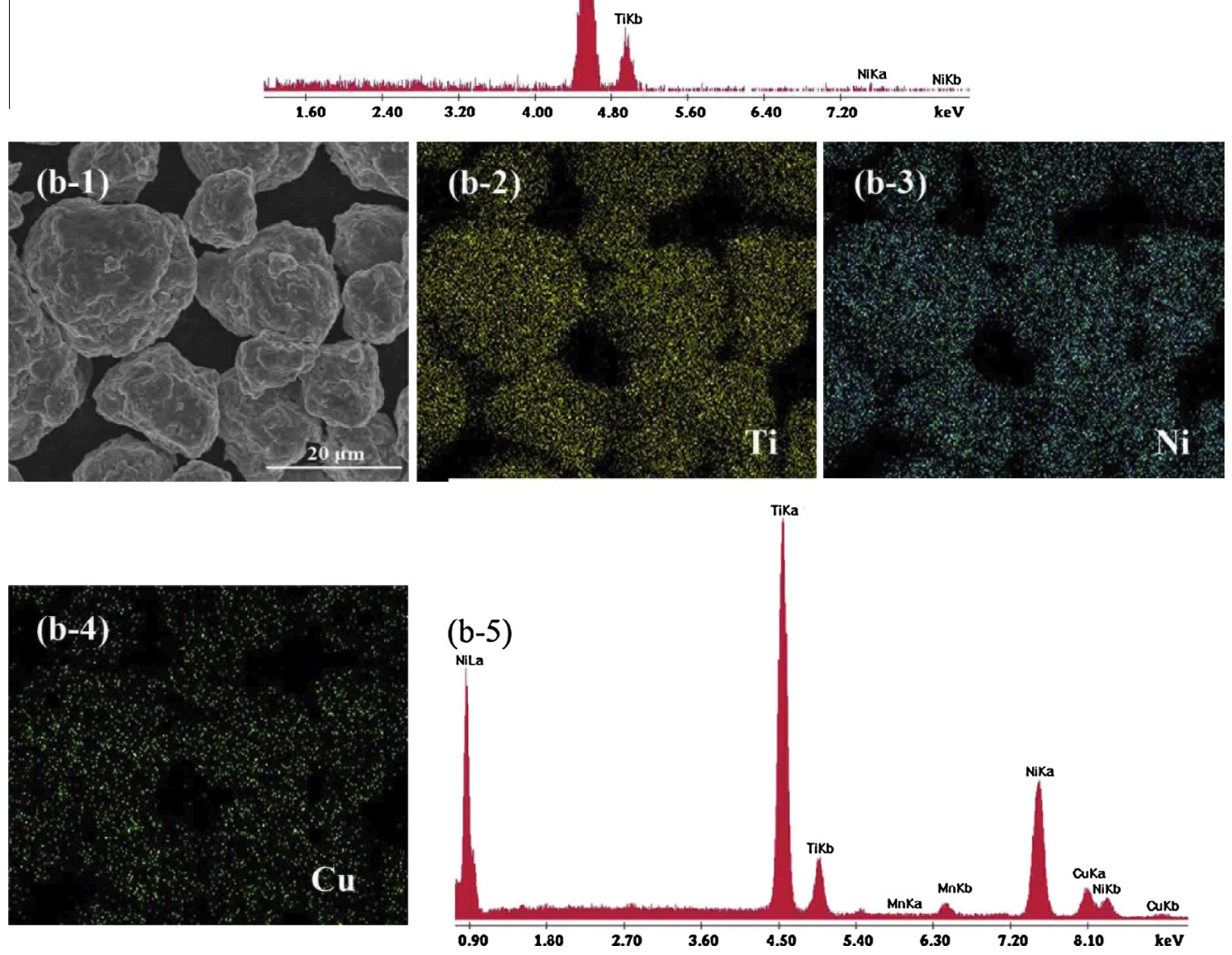

Fig. 3. Elements distribution in the $1 \mathrm{~h} \mathrm{(a)}$ and $48 \mathrm{~h}$ (b) milled powders. 

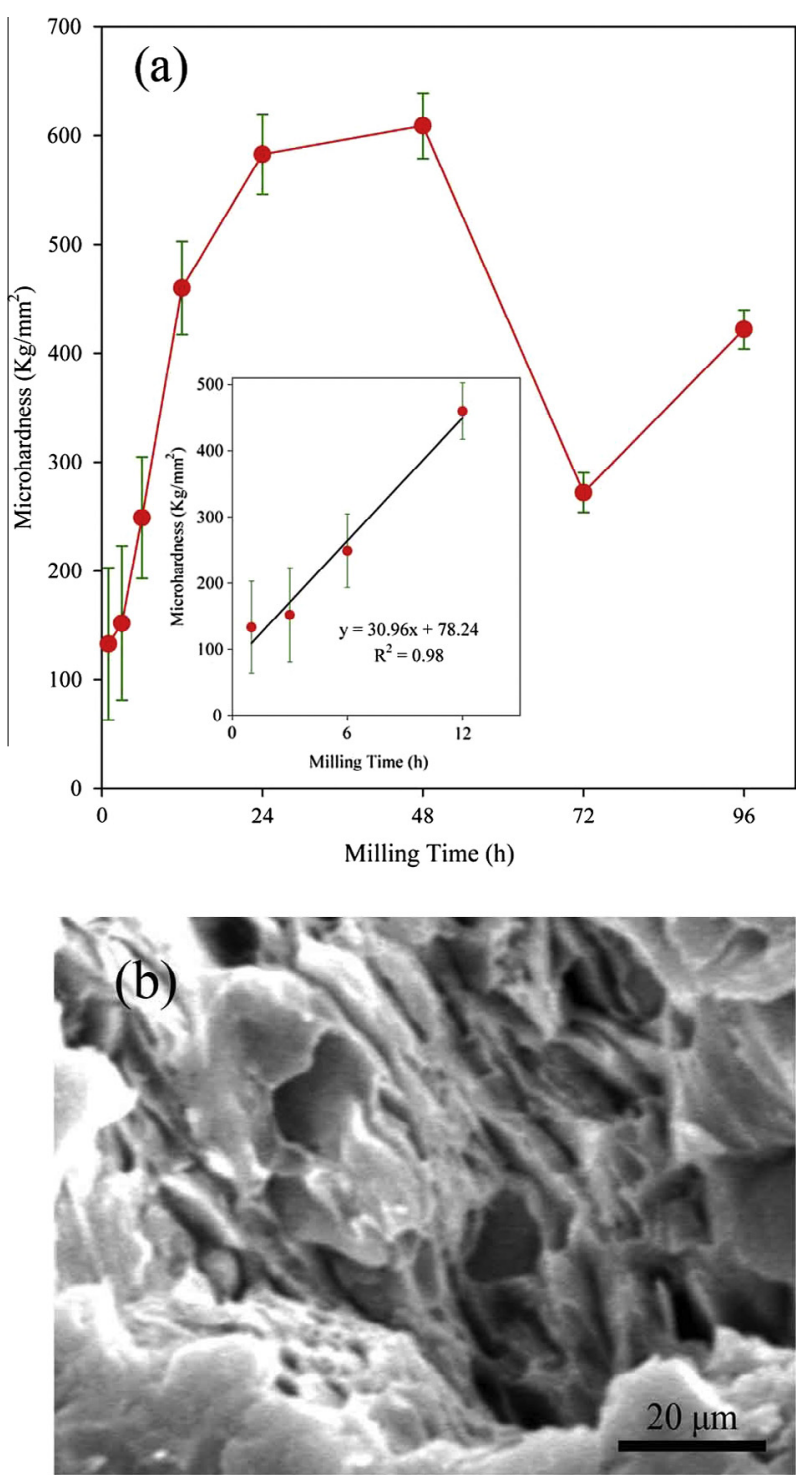

Fig. 4. (a) Variation of the Vickers microhardness of the prepared pellets as a function of milling time; (b) composite lamellar structure of the $3 \mathrm{~h}$ milled powder.

evidence of composition inhomogeneity is indicated in the EDS elemental mapping of Fig. 3(b).

\subsection{Microhardness test}

Fig. 4(a) depicts the average microhardness of the prepared pellets as a function of milling time. As is obvious in the results of the microhardness tests, the hardness is increased by the milling initiation and reaches its maximum value at $48 \mathrm{~h}$ of milling. Afterwards, at the $48-72 \mathrm{~h}$ interval, the hardness is drastically reduced, and finally re-increased. The increase in the hardness value with increasing the milling time is mainly attributed to the accumulation of strain energy [20]. In this regard, the decrease in the crystallite sizes with increasing the milling duration dominates the increase in the hardness values, except cases where new phases are formed. According to the structural analysis of the powders, at the milling interval of $0-48 \mathrm{~h}$, the amount of the hard amorphous phase increases and then (between $48 \mathrm{~h}$ and $72 \mathrm{~h}$ ) it is mechano-crystallized to the soft martensite phase. Subsequently, at the duration of 72-96 h, the fraction of the hard austenite phase is considerably enhanced. As it is apparent, the variations of the hardness values are compatible with the structural transformations during the milling cycle.

By estimating the variation of inter-layer thickness with milling time, the effectiveness of milling on the alloying process can be realized. According to the findings of Benjamin and Volin [26], the powder hardness varies linearly with milling time. At the early stages of milling (typically $0-12 \mathrm{~h}$ ), with some assumption, the inter-layer thickness can be calculated from the following equations. The assumptions include (1) the constant energy input rate to the process and (2) the linear dependence of Vickers' hardness with the energy required per unit strain for a constant volume of material. The Vickers' hardness can be approximated by:

$H=A+B t$

where $H$ and $t$ are the Vickers' hardness and milling time, respectively. Therefore

$\ln \frac{L_{o}}{L_{t}}=\frac{K}{B} \ln \left(1+\frac{B}{A} t\right)$

where $K, A$, and $B$ are constants and $L$ represents the lamellar thickness. In the present alloying system, $A$ and $B$ can be calculated from

Table 3

Variation of layer thickness by milling time and the quantity of A, B, and K constants in Eq. (3).

\begin{tabular}{lll}
\hline Milling time $(\mathrm{h})$ & $L_{t}(\mu \mathrm{m})$ \\
\hline 1 & & 10.17 \\
3 & & 1.19 \\
6 & & 0.15 \\
12 & & $12 \times 10^{-3}$ \\
24 & $\mathrm{~B}$ & - \\
$\mathrm{A}$ & 30.96 & $\mathrm{~K}$ \\
78.24 & & 147.88 \\
\hline
\end{tabular}

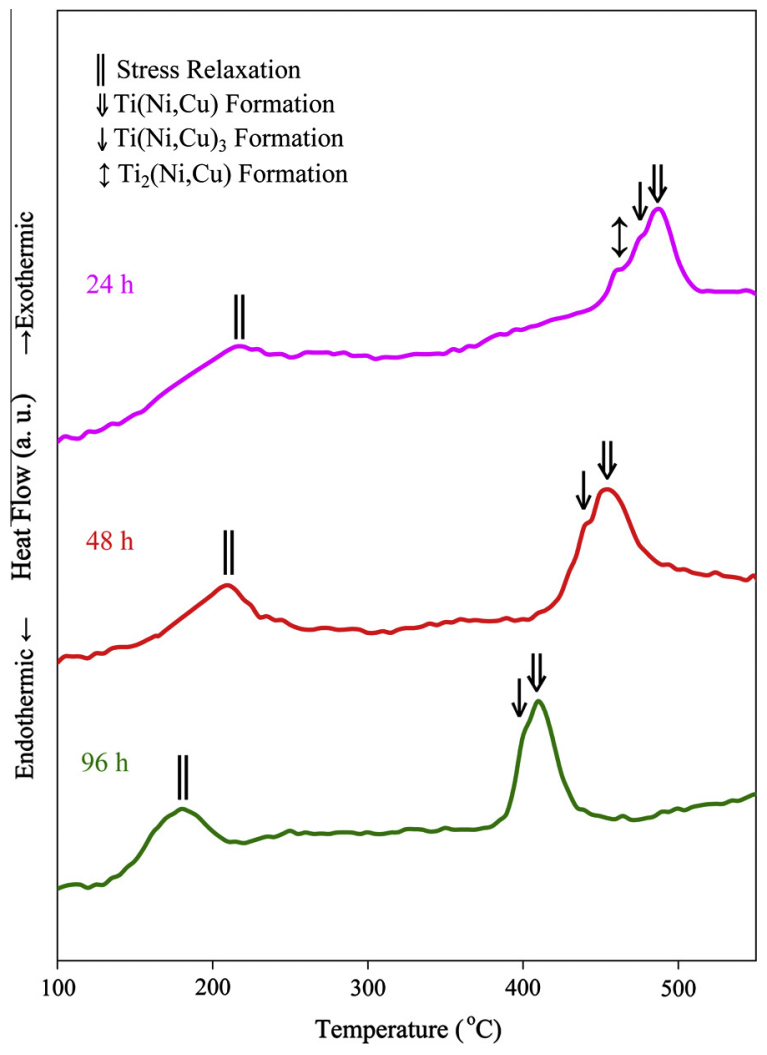

Fig. 5. DSC curve of the mechanically-alloyed $\mathrm{Ti}-\mathrm{Ni}-\mathrm{Cu}$ powders. 

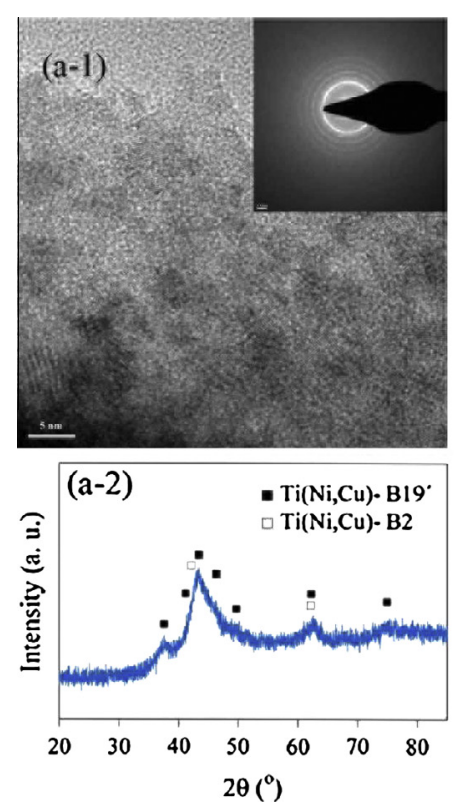
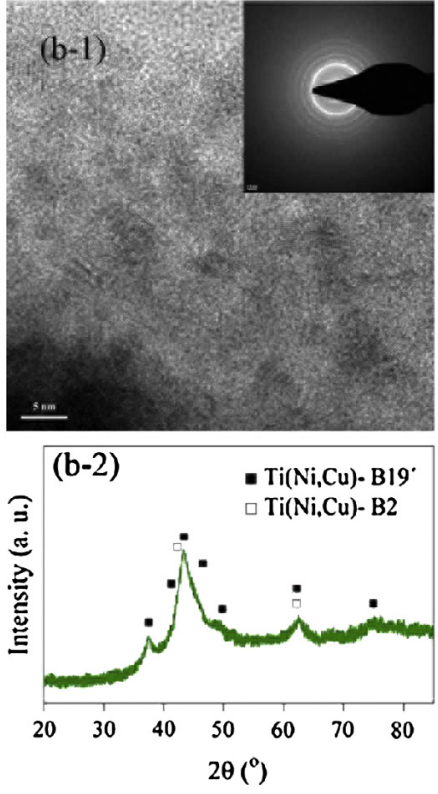
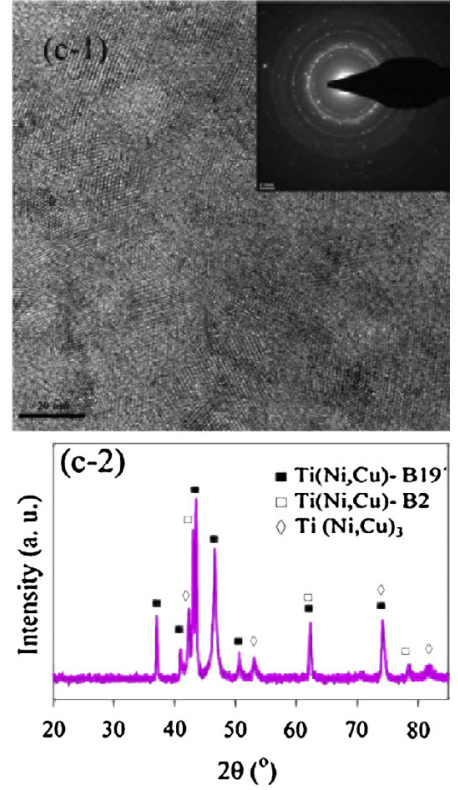

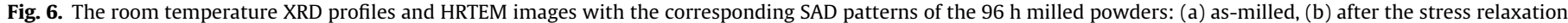
process $\left(250^{\circ} \mathrm{C}\right)$, and $(\mathrm{c})$ after crystallization process $\left(520^{\circ} \mathrm{C}\right)$.

the linear portion of the hardness curve of Fig. 4 (from $1 \mathrm{~h}$ to $12 \mathrm{~h}$ of milling). Moreover, the value of $K$ is estimated from Eq. (3), in which the average particle size of the initial powders mixture $(50 \mu \mathrm{m})$ and the lamellar thickness of $3 \mathrm{~h}$ milled powders (regarding Fig. $4(\mathrm{~b}) \approx 1.19 \mu \mathrm{m}$ ) are selected for $L_{0}$ and $L_{t}$, respectively. The variation of layer thickness by milling as well as the quantity of $A$, $B$, and $K$ constants are listed in Table 3 . As it is evident, by increasing the milling time, the average layer thickness severely decreases, and after $24 \mathrm{~h}$ of milling, it reaches a very small value, which indicates the completion of the alloying process at this moment, thereby confirming the qualitative and quantitative phase analyses done by XRD.

\subsection{Thermal behavior}

Fig. 5 shows the DSC plot of the as-milled powders in the temperature range of $100-550^{\circ} \mathrm{C}$. As it can be seen, two main exothermic events are detectable in the DSC curves of the samples.

In order to determine the origin of the events, heating cycles were conducted on selected milled powders similar to the heating procedure of DSC, where the samples were heated up to the temperatures well below and above the temperature ranges of the processes and subsequently were water quenched. Fig. 6 depicts the room temperature XRD profiles and HRTEM images with the corresponding SAD patterns of the $96 \mathrm{~h}$ milled sample before and after the heating cycles $\left(250^{\circ} \mathrm{C}\right.$ and $\left.520^{\circ} \mathrm{C}\right)$. According to the results, it can be found that the first peak in the DSC curve is correlated to the stress relaxation process, where no significant structural changes are detectable in the HRTEM image as well as XRD and SAD patterns of the sample well below and above of its temperature range. Furthermore, it is evident that the second exothermic event corresponds to the crystallization of the amorphous phase into more stable crystalline phases consisting B19', B2, and $\mathrm{Ti}(\mathrm{Ni}, \mathrm{Cu})_{3}$ phases. The existence of $\mathrm{B} 19^{\prime}$ in the XRD pattern is attributed to the partial transformation of B2-to-B19' during the cooling cycle, since the transformation temperatures are above room temperature.

Regarding the DSC profiles of Fig. 5, it is obvious that the crystallization temperatures decrease by increasing the milling time. The reason can be explained by the high density of defects generated during milling, which promotes the diffusive processes and facilitates the reordering phenomena [20]. On the other hand, nanocrystals created during milling can act as pre-existing nuclei for crystallization, thereby reducing the crystallization temperature.

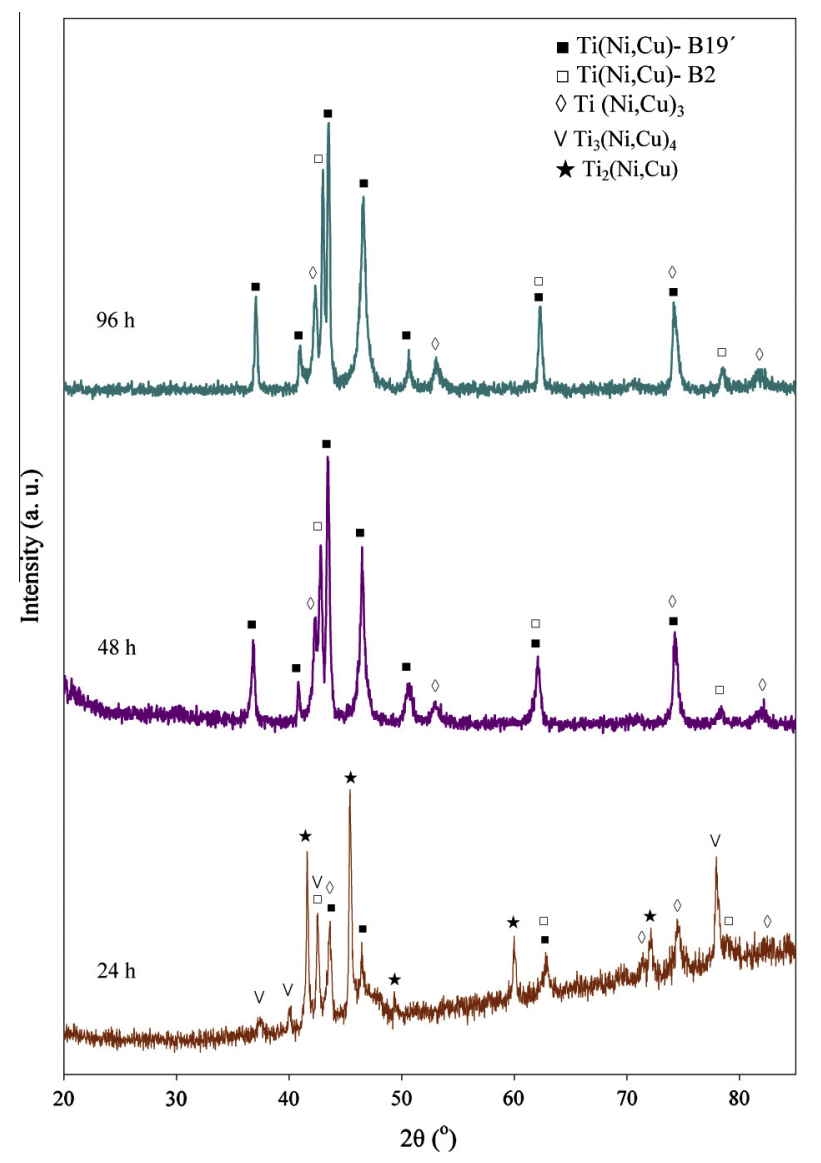

Fig. 7. Comparison between the XRD patterns of the powders milled for different milling times after the crystallization process $\left(520^{\circ} \mathrm{C}\right)$. 
Table 4

Variation of the phase content of the heat-treated samples by milling time.

\begin{tabular}{llllll}
\hline Milling time $(\mathrm{h})$ & ${\mathrm{B} 19^{\prime}}^{\prime}$ & $\mathrm{B} 2$ & $\mathrm{Ti}(\mathrm{Ni}, \mathrm{Cu})_{3}$ & $\mathrm{Ti}_{2}(\mathrm{Ni}, \mathrm{Cu})$ & $\mathrm{Ti}_{3}(\mathrm{Ni}, \mathrm{Cu})_{4}$ \\
\hline 24 & $26(2)$ & $10(1)$ & $13(1)$ & $29(2)$ & $22(2)$ \\
48 & $69(5)$ & $10(1)$ & $21(2)$ & - & - \\
96 & $57(4)$ & $30(2)$ & $13(1)$ & - & - \\
\hline
\end{tabular}

Error value $(X): \pm X$ wt.\%.

Fig. 7 compares the room temperature XRD pattern of $24 \mathrm{~h}$, $48 \mathrm{~h}$, and $96 \mathrm{~h}$ milled samples after the heating cycle to the temperature $\left(520^{\circ} \mathrm{C}\right)$ well above the crystallization temperatures. As it is clear, the existence of a considerable amount of $\mathrm{Ti}_{2}(\mathrm{Ni}, \mathrm{Cu})$, $\mathrm{Ti}(\mathrm{Ni}, \mathrm{Cu})_{3}$ (Table 3 ) is evident in the sample milled for $24 \mathrm{~h}$, which can be attributed to the presence of a considerable amount of Tiand $\mathrm{Ni}$-rich regions in the amorphous phase produced during the milling process. However, by the milling evolution (i.e. $48 \mathrm{~h}$ and $96 \mathrm{~h}$ ), due to the homogeneity increase, the quantity of $\mathrm{Ti}(\mathrm{Ni}, \mathrm{Cu})_{3}$ is significantly reduced and the $\mathrm{Ti}_{2}(\mathrm{Ni}, \mathrm{Cu})$ phase entirely diminishes, as shown in Table 4. It should be mentioned that the crystallization steps during the heating cycle clearly confirm the XRD results of Fig. 7. A more focus on the crystallization peaks of the DSC profiles of Fig. 5 reveals that in the $24 \mathrm{~h}$ milled sample, the crystallization process occurs at three steps containing the $\mathrm{Ti}(\mathrm{Ni}, \mathrm{Cu})_{3}, \mathrm{Ti}_{2}(\mathrm{Ni}, \mathrm{Cu})$, and $\mathrm{B} 2-\mathrm{Ti}(\mathrm{Ni}, \mathrm{Cu})$ formation, whereas the two-step crystallization (consisting the $\mathrm{Ti}(\mathrm{Ni}, \mathrm{Cu})_{3}$ and $\mathrm{B} 2-\mathrm{Ti}(\mathrm{Ni}, \mathrm{Cu})$ creation) governs in the samples milled for 48 and $96 \mathrm{~h}$. The formation of $\mathrm{Ti}(\mathrm{Ni}, \mathrm{Cu})_{3}$ and $\mathrm{Ti}_{2}(\mathrm{Ni}, \mathrm{Cu})$ phases prior to $\mathrm{Ti}(\mathrm{Ni}, \mathrm{Cu})$ can be explained by the basis of thermodynamic considerations. It was reported that in binary NiTi alloys [29], the driving force for the formation of $\mathrm{Ni}_{3} \mathrm{Ti}(\Delta H=140 \mathrm{~kJ} / \mathrm{mol})$ is stronger than that of $\mathrm{Ti}_{2} \mathrm{Ni}$ $(\Delta H=83 \mathrm{~kJ} / \mathrm{mol})$ and TiNi $(\Delta H=67 \mathrm{~kJ} / \mathrm{mol})$. Moreover, the phases indicate the negative Gibbs free energy over a wide temperature range in which the free energy of $\mathrm{Ni}_{3} \mathrm{Ti}$ and $\mathrm{Ti}_{2} \mathrm{Ni}$ is more negative than that of NiTi [30].

Concerning the aforementioned results, it can be implied that in the present alloying system not only the martensitic transformation start temperature (Ms) is above the room temperature, but also the martensitic transformation occurs at one step without the formation of intermediate R-phase. That is, the deviation of chemical composition from compound stoichiometry is negligible and the value of possible impurities is insignificant, which is in good agreement with the chemical composition results. Moreover, the potential to produce austenite (B2) as well as thermal- and stress-induced martensites (B19') indicates the compound susceptibility to show SME and SE. It should be noticed that the appropriate shape recovery and superelasticity were found in the prepared samples which will be reported elsewhere.

\section{Conclusions}

In the present paper, the effect of milling process on the chemical composition, structure, microhardness, and thermal stability of amorphous/nanocrystalline Ti-41Ni-9Cu compounds developed by mechanical alloying was investigated and the potential to produce B19' (thermal- and stress-induced) and B2 by mechanical alloying and subsequent annealing was established. The important observations are summarized as follows:

(1) The fraction of iron and chromium contaminations is significantly low at all milling times.

(2) During milling, the interlayer thickness was reduced and after $24 \mathrm{~h}$ of milling the alloying was completed.

(3) By milling initiation, the amorphous phase was rapidly formed and after $48 \mathrm{~h}$ of milling the mechanical crystallization of the phase to more stable B2 and B19' phase occurred.
(4) During milling, the powders microhardness was initially increased, then reduced, and afterward increased.

(5) During milling and subsequent heat treatment, the martensitic transformation occurred without the formation of intermediate pre-martensite phase (R-phase).

(6) In the present alloying system, the martensitic transformation start temperature (Ms) is above the room temperature.

(7) By increasing the milling time, the crystallization temperature of the amorphous phase decreased.

(8) By milling evolution, the thermal crystallization steps of the amorphous phase changed from 3 to 2 .

(9) By heating the powders milled for $24 \mathrm{~h}$, a considerable amount of $\mathrm{Ti}_{2}(\mathrm{Ni}, \mathrm{Cu})$ was formed in addition to B2 and B19́. Alternatively, for $96 \mathrm{~h}, \mathrm{Ti}_{2}(\mathrm{Ni}, \mathrm{Cu})$ was eliminated and the quantity of B19 was increased.

\section{Acknowledgements}

Parts of this work was supported by EU FP7 Marie Curie IRG Grant 239444, COST NanoTP, TUBITAK Grants 108E163, 109E044, $112 \mathrm{M} 004$ and 112E052.

\section{References}

[1] Pelton AR, Stöckel D, Duerig TW. Medical uses of nitinol. Mater Sci Forum 2000;327-328:63-70.

[2] Thompson SA. An overview of nickel-titanium alloys used in dentistry. Int Endod J 2000;33:297-310.

[3] Humbeeck JV. Non-medical applications of shape memory alloys. Mater Sci Eng A 1999:273-275:134-48.

[4] Stoeckel D. Shape memory actuators for automotive applications. Mater Des 1990;11(6):302-7.

[5] Predki W, Knopik A, Bauer B. Engineering applications of NiTi shape memory alloys. Mater Sci Eng A 2008;481-482:598-601.

[6] Huang W. On the selection of shape memory alloys for actuators. Mater Des 2002;23:11-9.

[7] Otsuka K, Ren X. Physical metallurgy of Ti-Ni based shape memory alloys. Prog Mater Sci 2005;50:511-678.

[8] Lagoudas DC. Shape memory alloys modeling and engineering applications. Texas: Springer; 2008

[9] Haider W, Munroe N, Pulletikurthi C, Singh Gill PK, Amruthaluri S. Comparative biocompatibility analysis of ternary nitinol alloys. J Mater Eng Perform 2009; 18:760-4.

[10] Phukaoluan A, Khantachawana A, Kaewtatip P, Dechkunakorn S, Anuwongnukroh N, Santiwong P, et al. Property improvement of TiNi by $\mathrm{Cu}$ addition for orthodontics applications. Appl Mech Mat 2011;87:95-100.

[11] Potapov PL, Shelyakov AV, Schryvers D. On the crystal structure of TiNi-Cu martensite. Scr Mater 2001:44:1-7.

[12] Bhaumik SK, Saikrishna CN, Ramaiah KV, Venkataswamy MA. Understanding the fatigue behavior of NiTiCu shape memory alloy wire thermal actuators. Key Eng Mat 2008:378-379:301-16.

[13] Van Loo FJJ, Bastin GF, Leenen AJH. Phase relations in the ternary Ti-Ni-Cu system at 800 and $870^{\circ} \mathrm{C}$. J Less-Common Met 1978;57:111-21.

[14] Fukuda T, Saburi T, Chihara T, Tsuzuki Y. Mechanism of B2-B19-B19́ transformation in shape memory Ti-Ni-Cu alloys. Mater Trans 1995;36:1244-8.

[15] Lin K, Wu S. Multi-stage transformation in annealed Ni-rich $\mathrm{Ti}_{49} \mathrm{Ni}_{41} \mathrm{Cu}_{10}$ shape memory alloy. Intermetallics 2010;18:87-91.

[16] Nam TH, Hur SG, Alan IS. Phase transformation behaviors of Ti-Ni-Cu shape memory alloy powders fabricated by mechanical alloying. Met Mater $1998 ; 4: 61-6$

[17] Valeanu M, Lucaci M, Crisan AD, Sofronie M, Leonat L, Kuncser V. Martensitic transformation of Ti50Ni30Cu20 alloy prepared by powder metallurgy. J Alloys Compd 2011;509:4495-8.

[18] Murty BS, Ranganathan S, Rao MM. Solid state amorphization in binary Ti-Ni, $\mathrm{Ti}-\mathrm{Cu}$ and ternary $\mathrm{Ti}-\mathrm{Ni}-\mathrm{Cu}$ system by mechanical alloying. Mater Sci Eng A 1992; 149:231-40.

[19] Rozner AG, Heintzelman EF, Buehler WJ, Gilfrich JV. Effect of addition of oxygen, nitrogen and hydrogen on microstructure and hardness of cast TiNi intermetallic compound. Trans ASM 1965;58:415-8.

[20] Suryanarayana C, Klassen T, Ivanov E. Synthesis of nanocomposites and amorphous alloys by mechanical alloying. J Mater Sci 2011:46:6301-15.

[21] Chang SH, Wu SK, Kimura H. Crystallization Kinetics of $\mathrm{Ti}_{50} \mathrm{Ni}_{25} \mathrm{Cu}_{25}$ melt-spun amorphous ribbons. Mater Trans 2006;47(10):2489-92.

[22] ASTM Designation E 384-99. Standard test method for microindentation hardness of materials. Philadelphia (PA):ASTM, 1999.

[23] Nishida M, Wayman CM, Honma T. Phase transformation in $\mathrm{Ti}_{50} \mathrm{Ni}_{47.5} \mathrm{Fe}_{2.5}$ shape memory alloy. Metallography 1986;19:99-113. 
[24] Weeber AW, Bakker H. Amorphization by ball milling. A review. Physica B 1988;153:93-135.

[25] Amini R, Alijani F, Ghaffari M, Alizadeh M, Okyay AK. Quantitative phase evolution during mechano-synthesis of $\mathrm{Ti}-\mathrm{Ni}-\mathrm{Cu}$ shape memory alloys. J Alloys Compd 2012;538:253-7.

[26] Benjamin JS, Volin TE. The mechanism of mechanical alloying. Metall Trans $1974 ; 5: 1929-34$.

[27] Lu L, Lai MO. Formation of new materials in the solid state by mechanical alloying. Mater Des 1995;16(1):33-9.
[28] Amini R, Shokrollahi H, Salahinejad E, Hadianfard MJ, Marasi M, Sritharan T. Microstructural, thermal and magnetic properties of amorphous/ nanocrystalline FeCrMnN alloys prepared by mechanical alloying and subsequent heat treatment. J Alloys Compd 2009;480:617-24.

[29] Neves F, Martins I, Correia JB, Oliveira M, Gaffet E. Reactive extrusion synthesis of mechanically activated Ti-50Ni powders. Intermetallics 2007;15:1623-31.

[30] Locci AM, Orru R, Cao G, Munir ZA. Field-activated pressure-assisted synthesis of NiTi. Intermetallics 2003;11:555-71. 